See Article page 51.

\section{Commentary: Valve-sparing root replacement: Who wants to live forever?}

\author{
Christopher Lau, MD, and Mario Gaudino, MD
}

Valve-sparing root replacement (VSRR) using the reimplantation technique continues be refined and indications for its use are being applied to an expanding population of patients. VSRR was initially applied to normal trileaflet aortic valves. As experience in this realm increased, valves with increasing amounts of aortic insufficiency or associated with increasingly large ascending or aortic root aneurysms were repaired. ${ }^{1,2}$ As isolated aortic valve repair techniques matured, an increasing number of morphologically abnormal aortic valves were spared using the VSRR technique with aortic valve repairs. ${ }^{3,4}$ More recently, numerous groups have reported success in applying the tricuspid aortic valve sparing reimplantation techniques to bicuspid aortic valves (BAVs). ${ }^{5,6}$

In this issue of the Journal, the Cleveland Clinic group reports their experience with VSRR in patients with BAV. ${ }^{7}$ Over a span of 15 years, 92 patients undergoing VSRR with BAV were compared with 515 patients with trileaflet aortic valves. Balanced-score matching was performed and 71 matched pairs were identified and compared. The Cleveland Clinic group continues their long history of excellent outcomes with aortic aneurysm surgery, reporting only a single operative mortality, minimal postoperative morbidity, and no patient leaving the operating room with mild or more aortic insufficiency. At 5 years of follow-up, greater-than-moderate aortic insufficiency was seen in $7.4 \%$ of BAV and $2.9 \%$ of tricuspid patients. Freedom from reoperation was $94 \%$ and $77 \%$ at 5 and 8 years, respectively, in the BAV group and $98 \%$ in the tricuspid group for the entire length of follow-up. The

\footnotetext{
From the Department of Cardiothoracic Surgery, Weill Cornell Medicine, New York, NY.

Disclosures: Authors have nothing to disclose with regard to commercial support.

Received for publication March 2, 2020; accepted for publication March 3, 2020; available ahead of print March 19, 2020.

Address for reprints: Mario Gaudino, MD, Department of Cardiothoracic Surgery,

New York Presbyterian/Weill Cornell Medicine, 525 E 68th St, New York, NY

10065 (E-mail: mfg9004@med.cornell.edu).

J Thorac Cardiovasc Surg 2022;163:67-8

$0022-5223 / \$ 36.00$

Copyright (c) 2020 by The American Association for Thoracic Surgery

https://doi.org/10.1016/j.jtcvs.2020.03.020
}
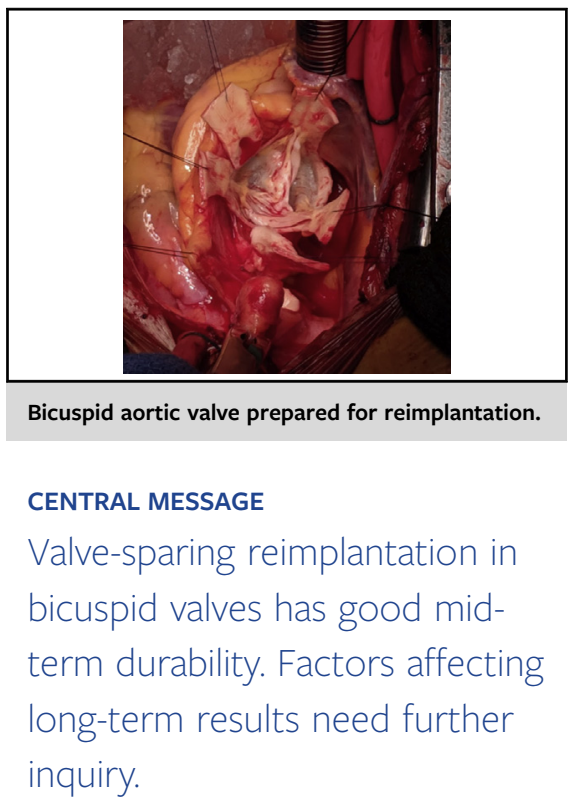

mid-term results were reassuring, but the authors voiced the need for longer-term follow-up due to the signs of potentially inferior durability such as more aortic insufficiency, greater mean gradients, less reverse left ventricular remodeling, and greater rate of reoperation.

Although the authors' concerns regarding the durability of VSRR in patients with BAV compared with tricuspid valves are legitimate, the true question is how to choose which patients with BAV should have their valves spared and which should be replaced. What needs to be elucidated is how to select patients and which techniques lead to better durability in long-term follow-up. In our recently published series of patients with BAV undergoing VSRR, there was $100 \%$ freedom from reoperation at 8 years of follow-up, but the number at risk at 8 years was relatively low, indicating a need for longer longitudinal follow-up. ${ }^{6}$ The current study shows us that this 5- to 10-year range is when spared BAVs may start to fail. While the basic reimplantation technique is the same across different centers, the finer technical details vary considerably. Future studies will need to determine which of these variations affect long-term durability: BAV root subtypes, leaflet features (Sievers class, amount of preoperative insufficiency, cusp length, commissural orientation, etc), graft size selection, graft type selection (neo-sinuses vs straight tube graft), need for cusp repair, and type of cusp repair.

In this series, the authors found higher gradients in the BAV group. Our group found this as well and identified that cusp repair was associated with higher gradients in follow-up. Whether cusp repair affects long-term durability 
remains to be seen. Despite substantial variability in surgical technique, the immediate and even 5-year outcomes are strikingly similar across many centers. ${ }^{5,6,8,9}$ Operative mortality and morbidity are always minimal, and patients leave the operating room with insignificant-to-no aortic insufficiency. At major centers, mid-term freedom from greater than moderate aortic insufficiency is $95 \%$ to $100 \%$ and freedom from reoperation is $94 \%$ to $100 \%$, as in the Cleveland Clinic series.

Of note, even if the durability of VSRR is inferior in patients with BAV, they may still stand to benefit from it compared with the alternative, which is replacement with a biologic or mechanical composite valve graft. As the authors state, VSRR with BAV is most often performed in younger patients whereas older patients receive aortic root replacement with bioprosthetic valve-conduits due to the excellent durability of tissue valves in the older population. ${ }^{10}$ The younger population is at risk of early bioprosthetic valve degeneration. Although a freedom from reoperation of $77 \%$ at 8 years for VSRR is not ideal, the alternatives of a bioprosthetic valve would also be associated with a greater-than-desired need for reoperation in a young population and a mechanical valve would guarantee the need for lifelong anticoagulation.

Mokashi and colleagues have presented a wonderful series of patients undergoing VSRR with either BAV or tricuspid aortic valves, reaffirming the evidence that immediate operative outcomes and mid-term outcomes are excellent and quite similar in both groups. Outcomes may start to diverge in longer-term follow-up, and the fear is that the early signs of reduced durability with BAV may eventually results in reoperations. However, the results of VSRR with
BAV do not need to be as good as VSRR with tricuspid valves, many of which seem to last forever. They mainly need to be at least comparable with a bioprosthetic valveconduit in terms of durability to be worthwhile.

\section{References}

1. Leyh RG, Kallenbach K, Karck M, Hagl C, Fischer S, Haverich A. Impact of preoperative aortic root diameter on long-term aortic valve function after valve sparing aortic root reimplantation. Circulation. 2003;108(suppl 1):II285-90.

2. Kallenbach K, Karck M, Leyh RG, Hagl C, Walles T, Harringer W, et al. Valvesparing aortic root reconstruction in patients with significant aortic insufficiency. Ann Thorac Surg. 2002;74:S1765-8; discussion S1792.

3. Settepani F, Cappai A, Basciu A, Barbone A, Moz M, Citterio E, et al. Impact of cusp repair on reoperation risk after the David procedure. Ann Thorac Surg. 2016; 102:1503-11.

4. Bavaria JE, Desai N, Szeto WY, Komlo C, Rhode T, Wallen T, et al. Valvesparing root reimplantation and leaflet repair in a bicuspid aortic valve: comparison with the 3-cusp David procedure. J Thorac Cardiovasc Surg. 2015;149(2 suppl):S22-8

5. Kayatta MO, Leshnower BG, McPherson L, Zhang C, Lasanajak Y, Chen EP. Valve sparing root replacement provides similar mid-term outcomes in bicuspid and trileaflet valves. Ann Thorac Surg. 2018;107:54-60.

6. Lau C, Wingo M, Rahouma M, Ivascu N, Iannacone E, Kamel M, et al. Valvesparing root replacement in patients with bicuspid aortopathy: an analysis of cusp repair strategy and valve durability. J Thorac Cardiovasc Surg. October 24, 2019 [Epub ahead of print].

7. Mokashi SA, Rosinski BF, Desai MY, Griffin BP, Hammer DF, Kalahasti V, et al. Aortic root replacement with bicuspid valve reimplantation: are outcomes and valve durability comparable to those of tricuspid valve reimplantation? J Thorac Cardiovasc Surg. 2022;163:51-63.e5.

8. Aicher D, Langer F, Kissinger A, Lausberg H, Fries R, Schäfers H-J. Valvesparing aortic root replacement in bicuspid aortic valves: a reasonable option? J Thorac Cardiovasc Surg. 2004;128:662-8.

9. Kari FA, Liang DH, Kvitting J-PE, Stephens EH, Mitchell RS, Fischbein MP, et al. Tirone David valve-sparing aortic root replacement and cusp repair for bicuspid aortic valve disease. J Thorac Cardiovasc Surg. 2013;145(3 suppl): S35-40.e1.

10. Gaudino M, Di Franco A, Ohmes LB, Weltert L, Lau C, Gambardella I, et al. Biological solutions to aortic root replacement: valve-sparing versus bioprosthetic conduit. Interact Cardiovasc Thorac Surg. 2017:24:855-61. 